\title{
Development and Use of Beremin Local Criterion for Cleavage Fracture in the Steel Industry
}

\author{
O. Cleizergues, T. Sturel, M. Difant and F. Mudry \\ IRSID, Voie Romaine, BP. 30320, 57283 Maizières-les-Metz, France
}

\begin{abstract}
This paper describes the use of Local Approach to Fracture in the French steel industry. The criteria used to model cleavage fracture of steels are briefly presented. Various applications covering a wide range of steels are reviewed. These applications illustrate the advantages of the Local Approach, such as scatter prediction, the ability to finely relate microstructure to mechanical properties and to take into account materials with heterogeneous microstructures such as welds. Finally, current developments of the method are presented. These developments will allow a quick and easy implementation of this procedure which will become accessible to industrial laboratories.
\end{abstract}

\section{INTRODUCTION}

The Local Approach to fracture was developed with the aim of giving a description of the fracture process close to the physical reality. Firstly applied for toughness prediction of nuclear pressure vessels steels, it soon was used for other applications and is now in growing use in the steel industry.

The immediate advantage of the Local Approach was to give a good description of phenomena poorly explained by linear fracture mechanics such as scatter and size effects. On the other hand, it required more work to interpret tests results with numerical simulations. That period is now over as developments of the methodology have turned it into an easily usable tool.

After a review of the methodology, various applications on steels of very different nature are presented. They illustrate the ability of the Local Approach to describe temperature and scatter effects. The specific advantages of the Local Approach, namely its ability to link toughness properties with microstructure and to assess complex situations such as heterogeneous materials are stressed. An example of toughness prediction for a weld is presented.

The last part of this paper presents current developments of the method with the aim of widening the scope of applications. Two objectives are followed : extending the predictions from the brittle behaviour to brittle-ductile transition behaviour, and easing the practical implementation.

\section{DESCRIPTION OF THE METHODOLOGY}

\subsection{The Beremin model}

The various applications presented here all rely on the cleavage criterion proposed by the Beremin group [1]. This criterion is based on two main features of the cleavage fracture mechanism in low carbon steels [2] :

- the instability of existing microcracks in the material. This is described with the critical cleavage stress concept, its scatter is taken into account using Weibull's statistic;

- the requirement of plastic deformation for the initiation of microcracks in the material. No microcracks are present if the plastic strain is zero.

For homogeneous material, a quantity called "Weibull stress" and denoted, $\sigma_{\mathrm{w}}$, is introduced : 


$$
\sigma_{w}=\sqrt[m]{\int_{P . Z} \sigma_{I}^{m} \frac{d V}{V_{0}}}
$$

where $\mathrm{m}$ is the exponent of Weibull's statistics, $\mathrm{V}_{0}$ an arbitrary unit volume and $\sigma_{1}$ the maximal principal stress. The integral is extended to the plastic zone because a local plastic deformation is needed to generate microcracks.

This value is then used to estimate the fracture probability :

$$
P_{f}=1-\exp \left(-\left(\frac{\sigma_{w}}{\sigma_{u}}\right)^{m}\right)
$$

where $P_{f}$ stands for the fracture probability and $\sigma_{u}$ is the critical cleavage stress for the elementary volume $\mathrm{V}_{0}$.

In the case of a multi-material, the survival of the structure is assured if each material individually remains intact. This weakest link assumption is written as follows :

$$
1-P_{f}^{\text {total }}=\prod_{\text {mat }, j}\left(1-P_{f}^{j}\right)=\exp \left[-\sum_{j}\left(\frac{\sigma_{w}^{j}}{\sigma_{u}^{j}}\right)^{m_{j}}\right]
$$

To apply this model, several steps are necessary:

- for each material, measurements of the stress-strain laws at different temperatures with conventional tensile specimens,

- elastic-plastic finite element simulation of the structure of interest,

- measurement of the cleavage fracture parameters $m$ and $\sigma_{u}$ for each material and a given $V_{0}$. Usually, this is done with round notched specimens tested at low temperatures where cleavage fracture occurs,

- use of a post-processing program for computing the probabilities of fracture of the structure as described above.

\subsection{Determination of local fracture parameters $m$ and $\sigma_{u}$}

Two collective research programs have highlighted the main steps of the procedure [3], [4], allowing to the proposal of guidelines for the practical implementation of the method. More details can be found in the draft procedure discussed by ESIS TC1 [5].

From the experimental point of view, the method is quite straightforward, as only tensile tests are performed. Measurement of the stress-strain law of the material must be conducted with great care. A precise control of the test temperature must be achieved. For the steel studied in [3], yield strength was shifted from $\sim 800$ to $\sim 1000 \mathrm{MPa}$ when the temperature was lowered from $-150^{\circ} \mathrm{C}$ to $-196^{\circ} \mathrm{C}$. An error of $\pm 2^{\circ} \mathrm{C}$ on the test temperature thus results in an error of $\pm 1 \%$ on the yield strength.

For experiments on round notched specimens, the important point is to select a test temperature to obtain a strain at fracture of the specimens in a range of 5 to $20 \%$. Above $20 \%$, the stress-strain law must be extrapolated and the numerical calculations lose their accuracy. In the low strain range, stresses are maximum at the outer surface of the specimen and early breaks may be caused by irregularities of the notch surface.

A numerical calculation is then necessary to relate strain at fracture of the specimen to the Weibull stress $\sigma_{\mathrm{w}}$. As the experiments are always conducted with round notched specimens, these calculations differ only by the stress-strain law used. In order to simplify this repetitive numerical procedure, a master set of calculations has been performed. It covers all the range of materials commonly tested [4].

To obtain a universal description of the stress-strain laws, the Ludwig-Holomon formulation $\sigma=k \varepsilon^{\mathrm{n}}$ was used. As $k$ is simply a multiplier, selecting adequate values of $n$ ranging from $n=0.01$ to $n=0.3$ describes most materials of engineering interest. It has been shown that very accurate results could still be obtained 
even when two pairs of $(k, n)$ values, $\left(k_{1}, n_{1}\right)$ for $\varepsilon<\varepsilon_{0}$ and $\left(k_{2}, n_{2}\right)$ for $\varepsilon \geq \varepsilon_{0}$, were necessary to describe the stress-strain law. This case is frequently encountered when studying steels presenting a yield point. All numerical simulations for the various geometries of round notched specimens have been carried out.

Once the stress-strain law of the material has been expressed acccordingly to the equation $\sigma=k \varepsilon^{n}$, the results are quickly found in the corresponding graph. Such a graph is presented in figure 1. It summarizes results obtained for a round notched specimen with a minimum diameter of $10 \mathrm{~mm}$, a $2 \mathrm{~mm}$ notch radius and $n=0.15$. The evolution of $\sigma_{\mathrm{w}} / \mathrm{k}$ is given as a function of the mean strain of the specimen, for various values of the parameter $\mathrm{m}$. Input of strain at fracture of the specimen directly gives the relevant value of $\sigma_{\mathrm{w}} / \mathrm{k}$ for the experiment performed. This procedure is presented in detail in another paper in this conference [6].

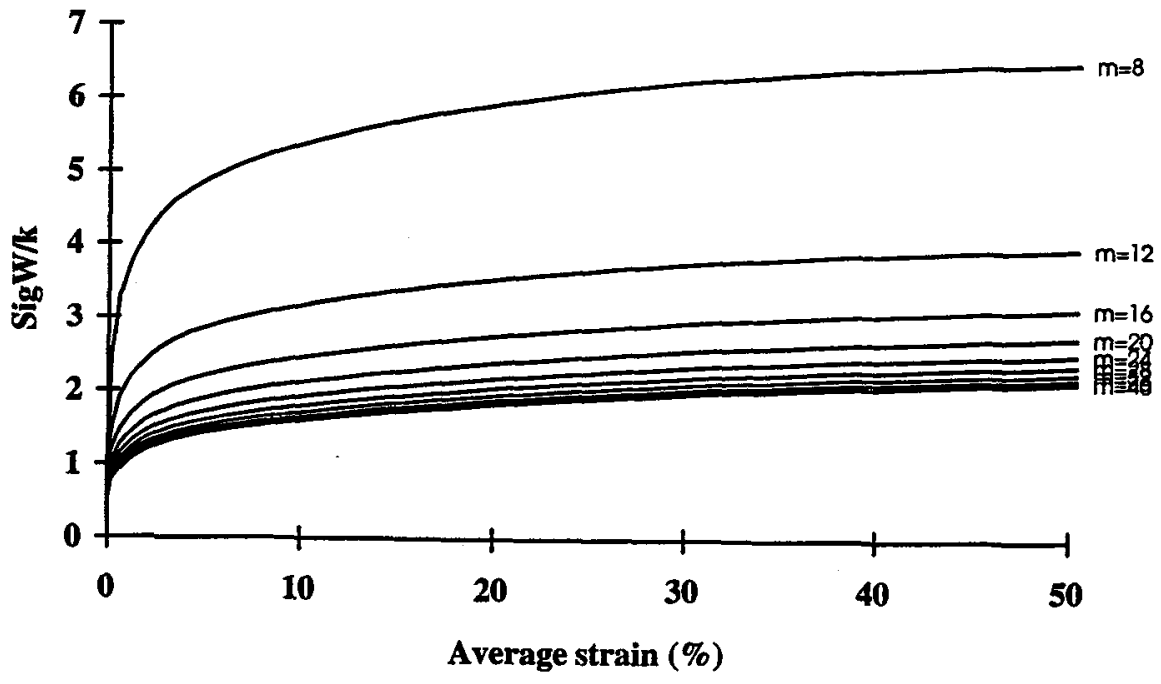

Figure 1 : Example of graph for direct interpretation of experiments on round notched specimens; value of $\sigma_{\mathrm{w}}$ at fracture is deduced from strain at fracture.

\section{PREDICTION OF FRACTURE TOUGHNESS PROPERTIES OF STEELS AS FUNCTION OF THEIR MICROSTRUCTURE}

\subsection{Prediction of fracture toughness}

One of the benefits which can be expected from the Local Approach to Fracture is the reduction of experimental delays and costs, through the ability of the method to predict experimental scatter and temperature effects. Experiments with round notched specimens are both easier and cheaper to perform than experiments with conventional fracture mechanics specimens. Yet, to describe precisely the experimental scatter a statistically significant number of specimens must still be used.

The two approaches have been conducted using a XC 48 ferritic-pearlitic steel. Conventional measurements of toughness were conducted with CT specimens ( $W=50 \mathrm{~mm}, \mathrm{~B}=25 \mathrm{~mm}, \mathrm{a} / \mathrm{W}=0.5)$. The assessment of toughness through the Local Approach method requires a set of experiments to determine the Beremin model parameters (here $V_{0}=[0.1 \mathrm{~mm}]^{3}, m=12$ and $\sigma_{\mathrm{u}}=4320 \mathrm{MPa}$ ). These experiments are conducted on round notched specimens at a chosen temperature. To expand the toughness prediction to other temperatures, only conventional tensile results are necessary. These allow us to predict toughness 
levels corresponding to a given failure probability. Probability levels of 0,1 and 0,9 are usually sufficient to describe the experimental scatter band.

A comparison of experimental and predicted fracture toughness values is presented in figure 2 , where $\mathrm{K}_{\mathrm{J}}$ is the value of $\mathrm{K}$ derived from $J_{1 \mathrm{c}}$ using the elastic formula in plane strain :

$$
J=\frac{K_{J}^{2}\left(1-v^{2}\right)}{E}
$$

where $\mathrm{E}=200000 \mathrm{MPa}$ is Young's modulus and $v=0.3$ is the Poisson ratio.

The accuracy of the prediction is very good. Results obtained with CT specimens fit in the predicted scatter band. A few experimental results corresponding to $\mathrm{K}_{\mathrm{J}}$ values close to the limit load of the specimens are slightly out of the predicted bounds. The trend of the results and the experimental scatter are correctly predicted over a wide temperature range corresponding to the lower part of the transition curve.

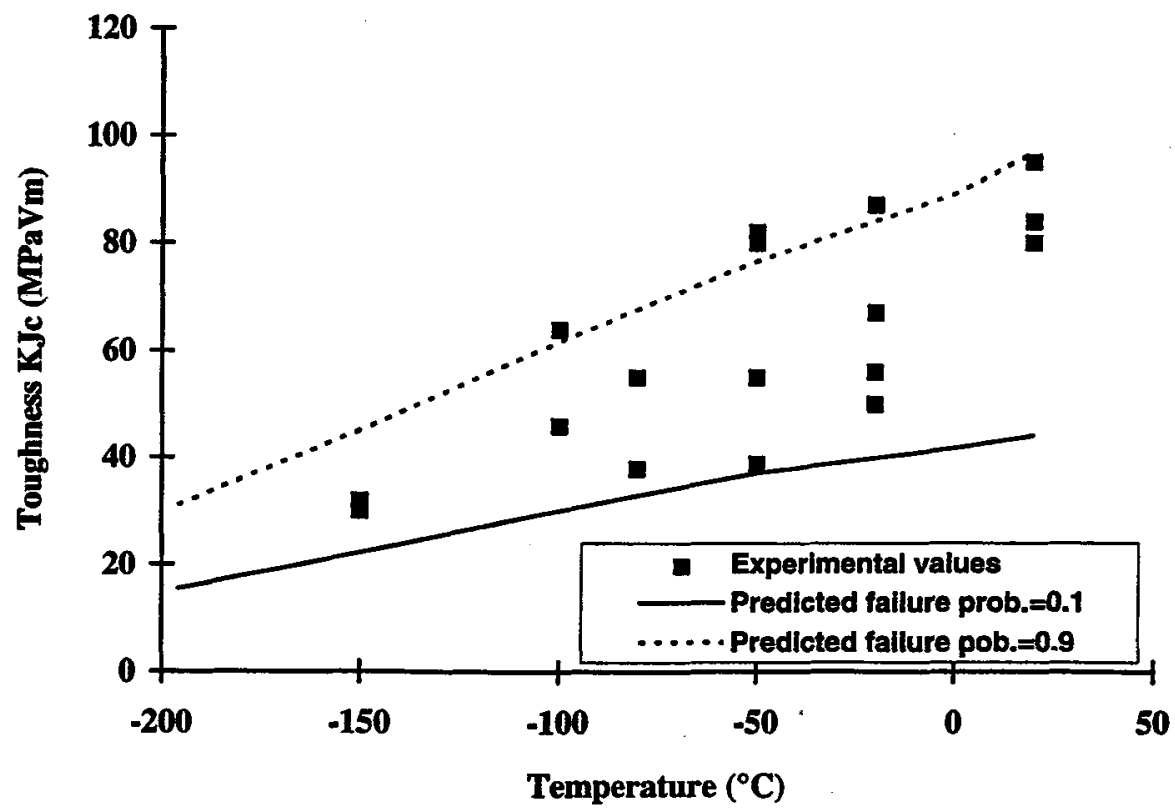

Figure 2 : XC-48 ferritic-pearlitic steel. Comparison between experimental toughness values and the toughness scatter band predicted using the Beremin model.

\subsection{Relation between mechanical properties and microstructure}

As long as cleavage fracture prevails, fracture toughness may be considered as a measure of the relative level between the stresses at a crack tip and the critical cleavage stress. The stresses at the crack tip are controlled mainly by the stress-strain law while the critical cleavage stress is a function of the size of the cleavage initiation sites, which are usually carbides in steels.

Another advantage of the Beremin model is to measure independently the two main parameters influencing fracture toughness and thus to relate the macroscopic properties to the components of the microstructure. 
For example, figure 3 shows the relation between the critical cleavage stress $\sigma_{c}$ and the size of the more brittle components that has been measured for different low carbon high strength steels. For fully pearlitic steels a similar relation has been established between $\sigma_{\mathrm{c}}$ and the pearlitic colony size.

This leads to two possible applications. Once the controlling parameters for the stress-strain laws are known, it is possible to predict fracture toughness values starting only from a microstructural observation. The reverse approach is also possible when looking for a new steel with a given compromise between toughness and yield strengh. The microstructural components responsible for critical cleavage stress levels and yield strength beeing known, it is then easier to choose the industrial process and the microstructure which will lead to the expected mechanical properties.

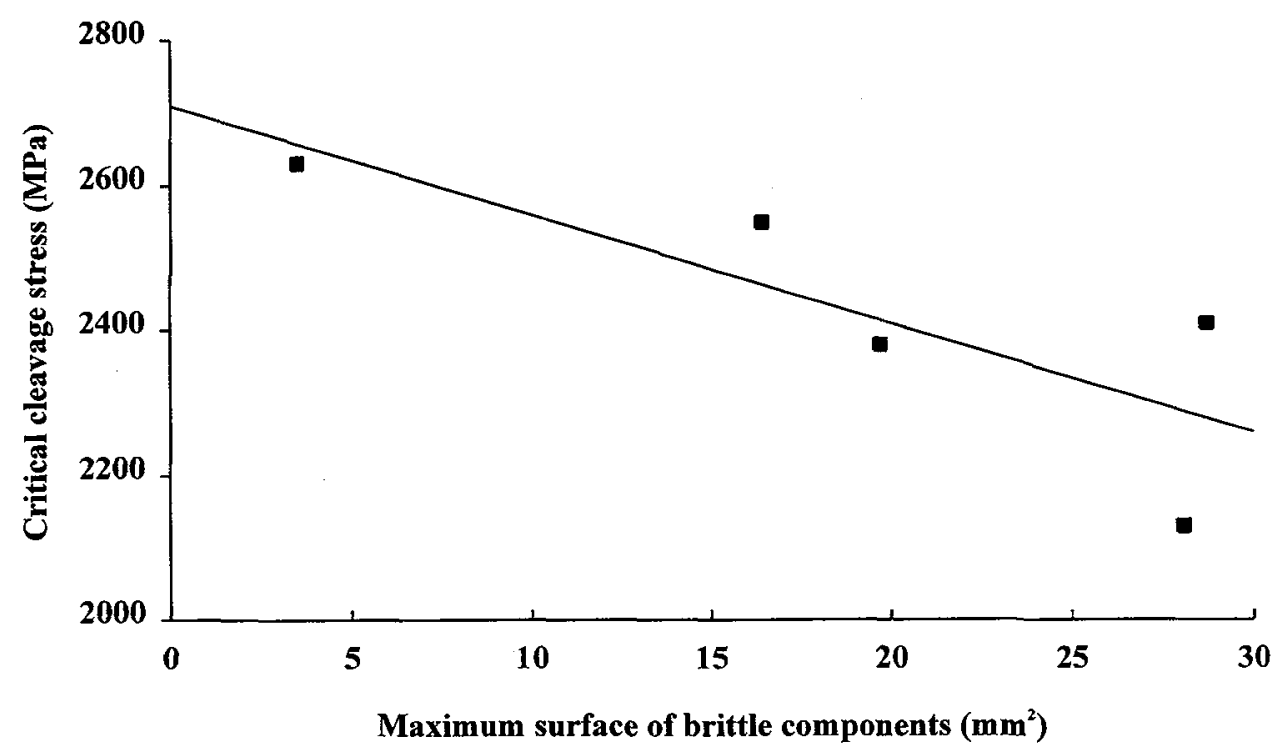

Figure 3 : Influence of the size of brittle components on the critical cleavage stress for a low carbon, high strengh steel.

\section{FRACTURE TOUGHNESS OF HETEROGENEOUS MATERIALS - APPLICATION TO WELDED JOINTS}

Fracture toughness tests results in the heat affected zone of welded joints usually reveal a large scatter. Therefore, numerous tests, which are both costly and time consuming, are required.

The Local Approach to brittle fracture has a high potential to overcome this problem : it includes an inherent statistical aspect and it is well adapted to treat the situation of inhomogeneous materials.

For one offshore steel, the method was checked in situations of increasing complexity: electron beam welding, monopass welding and multipass welding. The aim of this part is only to summarize the main results. Full details about this work may be found in reference 7 .

\subsection{Materials}

A carbon-manganese normalised steel plate with a thickness of $40 \mathrm{~mm}$ was studied. The chemical composition is given in table 3 . The microstructure is ferritic-pearlitic. 
Table 3: Chemical composition of the base steel (in $10^{-3}$ weight percent)

\begin{tabular}{|c|c|c|c|c|c|c|}
\cline { 2 - 7 } \multicolumn{1}{c|}{} & $\mathrm{C}$ & $\mathrm{Mn}$ & $\mathrm{Si}$ & $\mathrm{Ni}$ & $\mathrm{Cr}$ & $\mathrm{Mo}$ \\
\hline Base Metal & 170 & 1141 & 290 & 252 & 160 & 53 \\
\hline
\end{tabular}

The conventional properties at room temperature are given in table $4:$ yield strength (YS), ultimate tensile strength (UTS), elongation at fracture (A\%) and reduction of area $(\mathrm{Z} \%)$. This table also gives the temperature corresponding to a Charpy energy of $28 \mathrm{~J}$ (TK 28J), the Charpy energy at the ductile plateau and the local parameters for cleavage fracture $\left(\mathrm{m}\right.$ and $\sigma_{\mathrm{u}}$ ) corresponding to the base and weld metal and to different simulated heat affected zones.

Table 4 : Mechanical properties of base metal (transverse direction), simulated $\mathrm{HAZ}$ and weld metal at room temperature

\begin{tabular}{|c|c|c|c|c|c|c|c|c|}
\hline & \multicolumn{4}{|c|}{ Tensile Properties $\left(20^{\circ} \mathrm{C}\right)$} & \multicolumn{2}{|c|}{ Charpy V } & \multicolumn{2}{|c|}{ Local Criteria } \\
\hline & YS (Mpa) & $\begin{array}{c}\text { UTS } \\
(\mathrm{MPa})\end{array}$ & $\begin{array}{c}\mathrm{A} \\
(\%)\end{array}$ & $\begin{array}{c}Z \\
(\%)\end{array}$ & $\begin{array}{c}\text { TK 28J } \\
\left({ }^{\circ} \mathrm{C}\right) \\
\end{array}$ & $\begin{array}{c}\text { Duct. Lev. } \\
\text { (J) }\end{array}$ & $\mathrm{m}$ & $\sigma_{\mathrm{u}}(\mathrm{MPa})$ \\
\hline Base Metal & 356 & 540 & 33.0 & 74.0 & -70 & 173 & 15 & 2700 \\
\hline $1300^{\circ} \mathrm{C}+300 \mathrm{~s}$ & 489 & 656 & 25.5 & 65.9 & -20 & $>135$ & 16 & 2487 \\
\hline $1300^{\circ} \mathrm{C}+100 \mathrm{~s}$ & 583 & 766 & 20.7 & 70.8 & 20 & 200 & 16 & 2970 \\
\hline $1300^{\circ} \mathrm{C}+50 \mathrm{~s}$ & 905 & 1059 & 15.1 & 62.6 & 10 & $>80$ & 16 & 3780 \\
\hline Weld Metal & 451 & 571 & 23.2 & 79.0 & - & - & 16 & 2500 \\
\hline
\end{tabular}

$1300^{\circ} \mathrm{C}+100 \mathrm{~s}$ : Thermal treatment consisting in a rapid heating $\left(400^{\circ} \mathrm{C} / \mathrm{s}\right)$ up to $1300^{\circ} \mathrm{C}$ followed by a cooling treatment at a velocity measured by the time elapsed between $700^{\circ} \mathrm{C}$ and $300^{\circ} \mathrm{C}$, enabling to simulate different Heat Affected Zone microstructures.

\subsection{Electron beam welding}

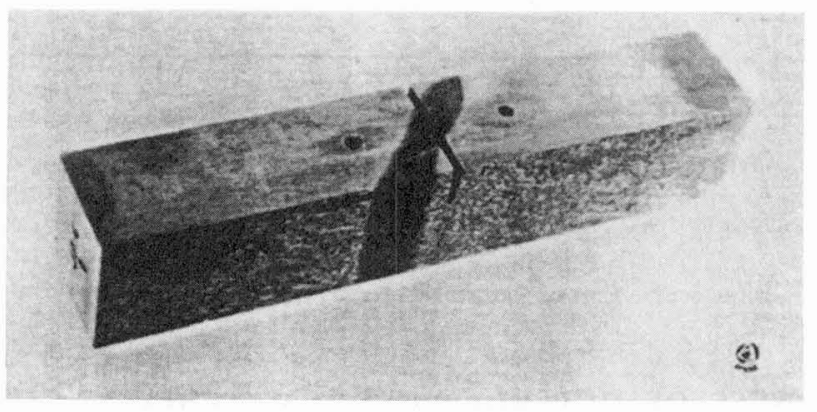

Figure 4 : SENB specimen ( $W=30 \mathrm{~mm}, B=15 \mathrm{~mm}$, $a / W=0.5$ ) with a brittle zone intercepting the notch.

Following the experimental technique developed by Kaplan and Devillers [8], an electron beam of $50 \mathrm{kV}$ and $320 \mathrm{~mA}$ was used to produce a small brittle zone $(5 \mathrm{~mm})$. In order to control the width of the fusion line, the angle of inclination was equal to $30^{\circ}$. In that case, Kaplan and Devillers demonstrated that the molten metal is comparable to a brittle zone with a $\Delta \mathrm{t}_{300}^{700}$ equal to $50 \mathrm{~s}$ in our conditions.

Single Edge Notched Bending (SENB) type specimens as shown in figure 4 were used. The main interest of this fracture mechanics specimen is that the crack front crosses a brittle zone of well defined dimensions.

For a cracked specimen, the stress field ahead the crack is only function of the applied K. Using the HRR stress field, the Beremin group has established the following relation : 


$$
\sigma_{w}^{m}=\frac{\sigma_{y}^{m-4} K_{I C}^{4} B C_{m}}{V_{0}}
$$

$\begin{array}{lll}\text { Where }: \sigma_{y} & \text { Yield strength } & \text { B Width of crack front } \\ & \mathrm{C}_{m} \quad \text { Parameter computed through finite element calculations. }\end{array}$

This relation can be expressed in terms of probability of fracture, formula (6). The probability of survival of a composite structure is the product of the probability of survival of each of its components. The equivalent toughness of a composite specimen, for a given probability of fracture can thus be easily evaluated.

$$
\ln \left(\frac{l}{1-P_{F}}\right)=\frac{\sigma_{w}^{m}}{\sigma_{u}^{m}} \sigma_{w}^{m}=\frac{\sigma_{y}^{m-4} K_{I C}^{4} B C_{m}}{V_{0} \sigma_{u}^{m}}
$$

The continuous lines give the predicted scatter band of toughness based on the theoretical approach described above to obtain the equivalent toughness values $K$ for a bimaterial. $K_{l c}, J_{1 c}$ and CTOD values were measured at different temperatures according to standard procedures. The results are given in figure 5. The agreement with experimental results is good.

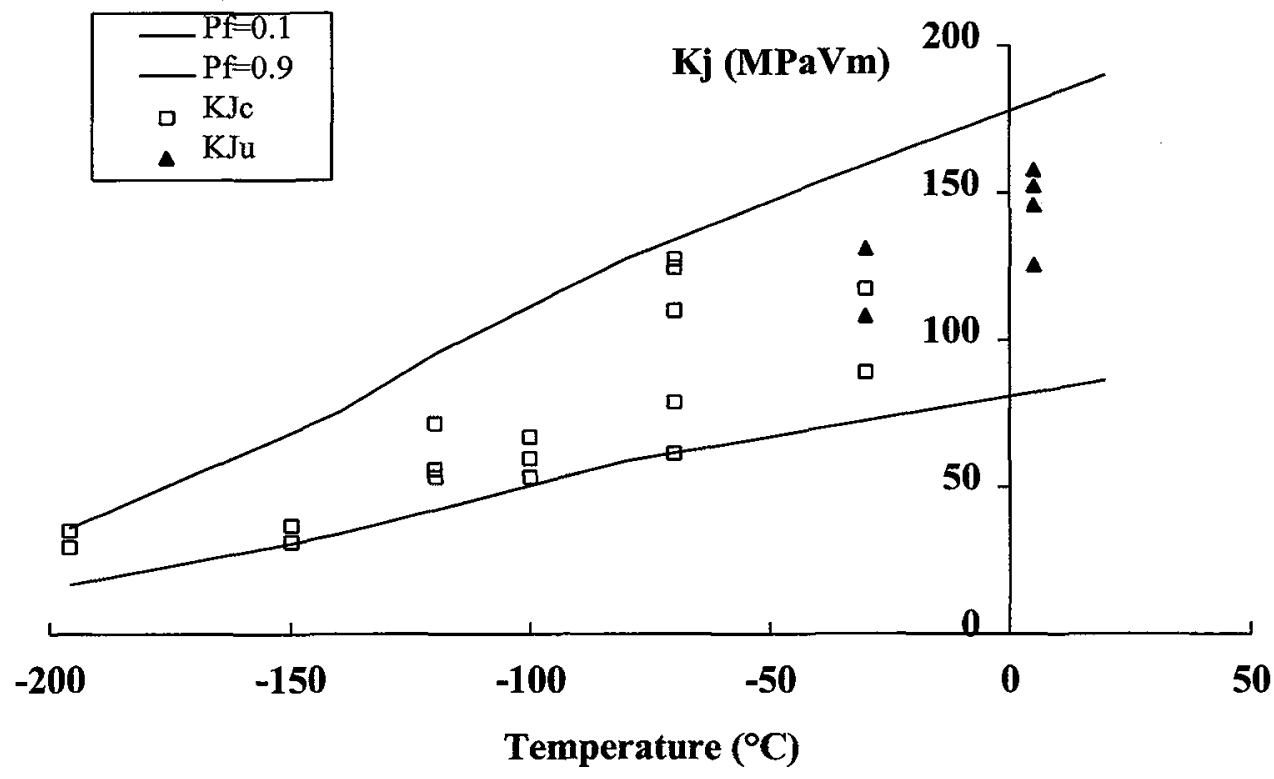

Figure 5 : Toughness as a function of temperature (points : experimental results, continuous lines : theoretical predictions; open squares correspond to pure cleavage, black triangles to cleavage with ductile initiation).

\subsection{SAW multipass welding}

Submerged Arc Welding (SAW) was carried out with wire electrodes in tandem configuration on a Kgeometry. The input energy was $40 \mathrm{~kJ} / \mathrm{cm}$ and the interpass temperature was $130^{\circ} \mathrm{C}$. There was no postheating or heat treatment after welding. Some of the welds were instrumented with thermocouples in order to measure the thermal cycle. Experimental values of $\Delta t_{300}^{700}$ were about $100 \mathrm{~s}$.

40 SENB specimens were machined in these multipass welds. Fatigue crack fronts were perpendicular to the metal plate and included in the HAZ on the vertical side of the K-weld geometry. 
CTOD was measured at $-40^{\circ} \mathrm{C},-20^{\circ} \mathrm{C}$ and $0^{\circ} \mathrm{C}$ following the standard $\mathrm{BS} 5762$. For each specimen, the fracture initiation sites were identified and the proportion of CGHAZ (coarse grained HAZ) encountered by the crack front was measured. Experimental results are plotted in figure 6 . A schematic view of the model is given in the upper right part of the figure. It does not correspond strictly to the experimental result but it is only a representation of what is taken into account by the equations. Despite the simplicity of this approach where only two zones (BM and HAZ) are modelled, the prediction agrees fairly well with experimental results. A very encouraging point is that this theoretical approach seems to be conservative but not in excess.

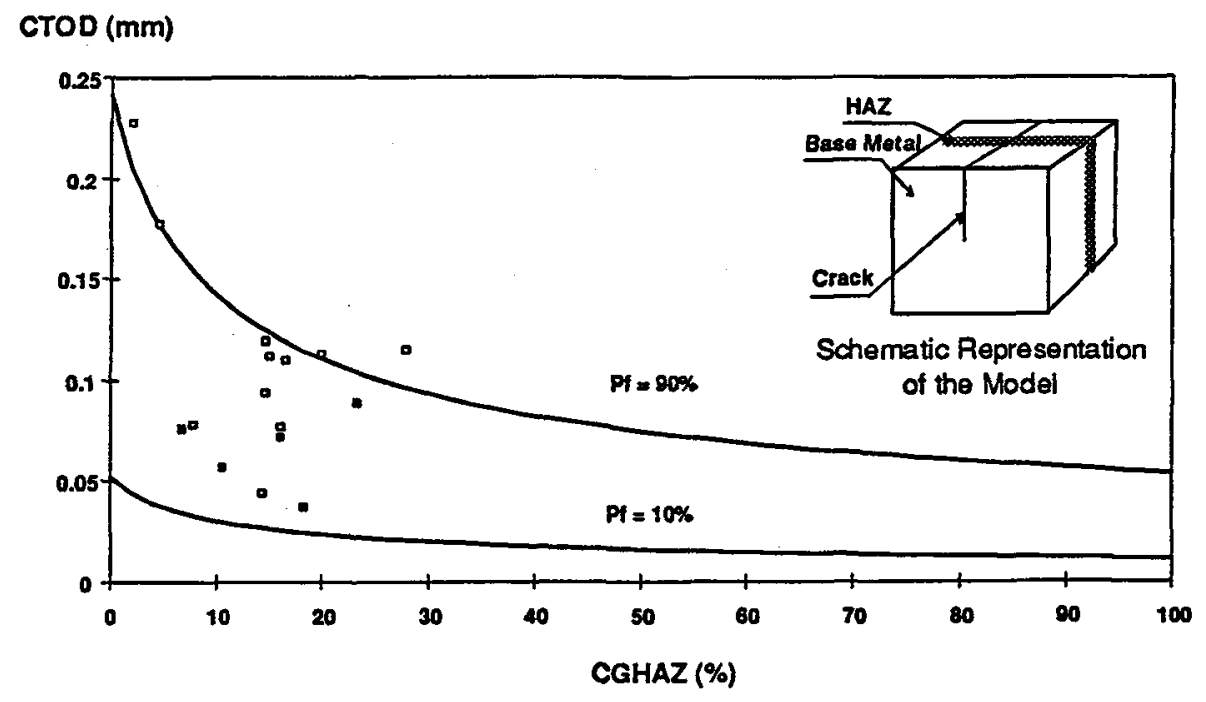

Figure 6 : Comparison of experimental points and theoretical CTOD results (respectively points and lines) for the multipass weld at $-40^{\circ} \mathrm{C}$.

\subsection{Application of the method}

The most interesting feature of the method is the possibility to rapidly obtain informations about fracture toughness properties of a weld and the associated scatter for cleavage fracture without carrying out numerous tests on precracked specimens. The following procedure is proposed :

- thermal simulation of the HAZ corresponding to the welding conditions

- tensile tests at different temperatures for the base, weld and simulated HAZ materials (smooth and round notched specimens)

- finite element simulation of fracture mechanics specimens which directly gives the fracture toughness prediction (scatter band) as a function of the proportion of brittle zone encountered by the crack front. 


\section{PERSPECTIVES - WORK IN PROGRESS}

\subsection{Modelling the brittle/ductile transition}

An important assumption made when using the Beremin model is that for a given material, $\sigma_{\mathrm{c}}$ has a constant value. This allows a correct prediction of toughness in the brittle temperature range. Extending the prediction into the transition temperature range requires to verify this assumption. Three parameters might influence the transition phenomenon : temperature is an obvious one, loading rate has a strong influence on results and strain is to be taken into account, because delayed fracture is often observed after extensive plastification of the specimens. The influence of these parameters is currently being investigated. Independence of $\sigma_{\mathrm{c}}$ relative to test temperature has been verified for one particular steel [9]. A similar experimental program is under way to study strain effects.

The main philosophy of the tests performed to assess the influence of temperature was to change the testing temperature while keeping the same strain at fracture, roughly $10 \%$ in our case. That was made possible by changing the specimen's geometry. Four types of round notched specimens have been used. These enabled the following test temperatures : $-196^{\circ} \mathrm{C}$ for half sized specimens with a $10 \mathrm{~mm}$ notch radius (NR), $-180^{\circ} \mathrm{C}$ for the full sized specimens with a $10 \mathrm{~mm} \mathrm{NR},-160^{\circ} \mathrm{C}$ with a $4 \mathrm{~mm} \mathrm{NR},-120^{\circ} \mathrm{C}$ with a $1 \mathrm{~mm}$ NR.

It is possible to estimate the critical cleavage stress by computing a mean value $\sigma_{u m}$ for each geometry and test temperature. A value of $\sigma_{w}$ is determined for each test through the equation (1). The mean value of $\sigma_{u m}$ is then given by :

$$
\sigma_{u m}=\frac{1}{N} \sum_{i=1}^{N} \sigma_{w i}
$$

The results are given in table 5 .

Table 5 : Effect of temperature on the critical cleavage stress $\sigma_{u}$

\begin{tabular}{|c|c|c|c|}
\hline $\begin{array}{c}\text { Specimen geometry } \\
\text { (number of tests) }\end{array}$ & Temperature $\left({ }^{\circ} \mathrm{C}\right)$ & $\begin{array}{c}\text { Mean strain at fracture } \\
(\%)\end{array}$ & $\begin{array}{c}\text { Mean critical cleavage } \\
\text { stress } \sigma_{\mathrm{um}}(\mathrm{MPa})\end{array}$ \\
\hline AE10-50\% (13) & -196 & 11.5 & 1980 \\
\hline AE10 (26) & -180 & 9.8 & 1932 \\
\hline AE4 (12) & -160 & 9.3 & 1926 \\
\hline AE1 (12) & -120 & 9.1 & 1913 \\
\hline
\end{tabular}

It can be seen that the critical cleavage stress can be considered as constant to within an accuracy of $4 \%$ (mean value $1940 \mathrm{MPa} \pm 2 \%$ ). This accuracy is sufficient for most of the applications of the Beremin model. Variations in the measured $\sigma_{\mathrm{u}}$ value result mainly from statistical distribution of the experimental results [10]. In this case, conducting tests at 4 temperatures restricted the number of specimens tested at each individual temperature, to keep the size of the experimental program reasonable. The scatter observed is not unusual relative to the number of specimens used.

\subsection{Methodology simplification}

To correctly describe the experimental scatter observed in the cleavage temperature range a relatively large number of specimens have to be tested. Our efforts are thus aimed at reducing the cost and complexity of these tests. This can be done by simplifying the tests themselves and their interpretation.

Work done in easing test interpretation has already be described in $\S 2.2$. Further developments are currently under way. Interpretation of each experimental result is still a repetitive process. This process will be greatly accelerated by computer based data analysis. The program developed will interpret each individual test result, then group all results to calculate parameters of the Beremin model. Finally toughness predictions will be made from these parameters.

As well as facilitating test interpretation, such a program will also be useful for materials design. Prediction of the final microstructure and tensile properties of a product from process parameters is now 
possible for certain applications. Feeding this data into the program would enable toughness prediction. The effect on toughness of a change in processing would thus be easily estimated. Such an approach would significantly reduce time and costs when designing new materials.

Reduction in the experimental effort could be achieved by replacing the experiments conducted with round notched specimens by experiments performed with Charpy specimens. If valid, this change in the testing procedure, will lead to a drastic diminution of the cost and complexity and duration of experiments. The method would then become readily applicable to industrial laboratories. Numerical simulations with a three dimensional model are currently being performed and an experimental program is under way. The challenge is to find an operational procedure to relate the fracture energy of the Charpy specimen to the Weibull's stress at fracture. A simple way of measuring Weibull's stress would then have been developed.

\section{CONCLUSION}

In this paper, various industrial applications have been presented. They illustrate the flexibility of the Local Approach to Fracture, using results obtained from steels with very different microstructures. The accuracy of the method is good and temperature and scatter effects are very well described.

The advantages of the Local Approach are stressed. It can distinguish between the various contributions of microstructure to toughness through tensile properties or critical cleavage stress variations. This is a powerful tool when developing new materials. The ability to take into account heterogeneous microstructures is also of great interest as illustrated by results obtained testing welded joints.

These benefits clearly established, Local Approach models are now more and more used in the steel industry and strong efforts are being made to ease their application. Work conducted thus far allows a drastic reduction in time necessary to interpretate tests results. The aim of current efforts is to reduce the experimental costs of the method.

\section{References}

[1] Beremin F.M., "A local criterion for cleavage fracture of a nuclear pressure vessel steel", Met. Trans. $A, 14$ A (1983) 2277-2287.

[2] Knott J.F., "Micro-mechanisms of Fracture and the Fracture Toughness of Engineering Alloys", 4th Int. Conf. on Fracture, vol. 1, pp.61-92, Canada, 1977.

[3] Mudry F., Di Fant M., "A Round Robin on the Measurement of Local Criteria for Fracture", (1994) European Commission report, EUR 15352 EN.

[4] Di Fant M., Le Coq V., Cleizergues O., Carollo G., Mudry F., Bauvineau L., Burlet H., Pineau A., Marini B., Koundy M., Sainte Catherine C., Eripret C. "Mise en place d'une méthođologie simplifiée pour utiliser des critères locaux de rupture", Final Report, MRES contract n 92.A.0334 (1996).

[5] ESIS "Draft procedure to measure and calculate local fracture criteria using notched tensile specimens" ESIS P6-94D, version 3.0, (1995).

[6] Di Fant M., Cleizergues O., Carollo G., Mudry F., Bauvineau L., Burlet H., Pineau A., Marini B., Koundy M., Sainte Catherine C., Eripret C "Development of a simplified approach for using the Local Approach to fracture", this issue.

[7] Sainte Catherine C., Di Fant M., Duquaire B., Balladon P. "Prediction of toughness scatter in heat affected zones with Local Approach", Eng. Fract. Mech., 46-1, (1993) 115-125.

[8] Kaplan D., Devillers L., "Propriétés d'emploi d'assemblages obtenus par faisceau d'électrons de tôles de forte épaisseur en acier de construction", Final Report, ECSC n ${ }^{\circ} 7210 / \mathrm{KA} / 310,1985$.

[9] Di Fant M., Carius H., Carollo G., Cleizergues O., Le Coq, V., Mudry F. "Local Approach to brittle fracture : Discussion of the effects of temperature and strain on the critical cleavage stress", $2^{\text {nd }}$ Griffiths Conf. on Micromecanisms of Fracture and their Structural Significance, Sheffield, $13^{\text {th }}-15^{\text {th }}$ Sept. 1995.

[10] Khalili A., Kromp K., "Statistical properties of Weibull estimators", J. of Mat. Sci. 26, pp 6741$6752,(1991)$. 